\title{
Kinetic Study on Pyrolysis of Polyphenylene Sulfide under Different Oxygen Concentrations
}

\author{
Chenzi Teng \\ College of Resources and Civil Engineering \\ Northeastern University \\ Shenyang, Liaoning, P.R.China \\ tengczlucky@163.com \\ Ning Mao \\ College of Resources and Civil Engineering \\ Northeastern University \\ Shenyang, Liaoning, P.R.China \\ maoning@mail.neu.edu.cn
}

\author{
Jingxian Liu \\ College of Resources and Civil Engineering \\ Northeastern University \\ Shenyang, Liaoning, P.R.China \\ 82003@126.com \\ Xinjiao Tian \\ College of Resources and Civil Engineering \\ Northeastern University \\ Shenyang, Liaoning, P.R.China \\ 1059878326@qq.com
}

\begin{abstract}
Kenitic of thermal degradation of PPS were studied undernitrogen, oxygen and airin formal works. The integral Coats-Redfern method based on single heating rate is employed for the kinetic analysis of the pyrolysis processunder different oxygen concentrations. The results indicated that only one stage occurred under pure nitrogen atmos- phere while two stages occurred under oxidative atmosphere. Maximal mass loss rate and apparent activation energy of the first stage varies little (Maximal mass loss rate of first degradation stage stabilizes $(4.3 \pm 0.5) \% \cdot \mathrm{min}^{-1}$, and apparent activation energy of the first degradation stage fluctuate around $170 \mathrm{~kJ}^{\circ} \mathrm{mol}^{-1}$ ) while corresponding kinetic parameters of the second stage increase linearly with increasing oxygen concentrations (at 10\%, 20\%, 30\%, $40 \%$, $50 \%, 60 \%$ ), in addition, apparent kinetic compensation effect of PPS under oxidative atmosphere was also discovered and discussed. The isokinetic temperature $T_{S}$ is $505^{\circ} \mathrm{C}$ and $522.4^{\circ} \mathrm{C}$ respectively with heating rate of $10 \mathrm{k} \cdot \mathrm{min}^{-1}$ and $20 \mathrm{k} \cdot \mathrm{min}^{-1}$.
\end{abstract}

Keywords-PPS;apparent

activation energy; pre-exponen-tial factor; apparent kinetic compensation effect; different oxygen concentrations

\section{INTRODUCTION}

Polyphenylene sulfide has been widely used in automobile, chemical, building material industry and environmental protection for the sake of excellent fire retardancy, heat durability, corrosion resistance and mechanical property since industrialized production[1]. Instability of outermost electron of the divalent sulphur atom results in its tendency to lose electrons and react with oxygen atom, furthermore, the macromolecular chains broken and degradation occurs[2]. The mechanical properties such as breaking tenacity and elongation of PPS fiber was investigated[3][4][5],kinetic analyzed thermal behaviors of PPS in the present only concentrates on the nitrogen atmosphere, air atmosphere, or the comparison of them. In order to study the effects of oxygen on the degradation of polyphenylene sulfide, a set of thermagravimetric experiments under different oxygen concentrations were carried out.

\section{EXPERIMENTAL SECTION}

Thermo gravimetric experiments were conducted on Netzsch STA 449F3 analyzer and Proteous thermal software. Approximately, 6mg of polyphenylene sulfide fiber samples from Toray of Japan were used for each experiment. Samples were heated from $30^{\circ} \mathrm{C}$ to $700^{\circ} \mathrm{C}$ with two heating rates $\left(10 \mathrm{~K} \cdot \mathrm{min}^{-1}, 20 \mathrm{~K} \cdot \mathrm{min}^{-1}\right)$ under $\mathrm{N}_{2}-\mathrm{O}_{2}$ mixture with different oxygen concentration $(0 \%$, $10 \%, 20 \%, 30 \%, 40 \%, 50 \%, 60 \%$ ), and all tests were carried out with a total flow rate of $100 \mathrm{ml} \cdot \mathrm{min}^{-1}$.

\section{RESULTS AND DISCUSSION}

\section{A. Pyrolysis characteristic analysis}

Thermogravimetry (TG) curves under various oxygen percentages are illustrated in Fig. 1 and Fig. 2 respectively for heating rates of $10 \mathrm{k} / \mathrm{min}$ and $20 \mathrm{k} / \mathrm{min}$. Initial degradation temperature stabilize around $480^{\circ} \mathrm{C}$ and increase with the increasing heating rates. In pure nitrogen the degradation involves only one stage with the weight loss ratio of $43 \%$ and terminated pyrolysis temperature of $580^{\circ} \mathrm{C}$ and $595^{\circ} \mathrm{C}$ for two heating rates respectively. When oxy- gen is present, two degradation stages occur and the first stage is independent of oxygen concentration with the TG curves nearly overlapped. In addition, the terminated temperature of first stage is located in range of $550-610^{\circ} \mathrm{C}$ and $575-615^{\circ} \mathrm{C}$ and decrease with the increasing oxygen percentages. Divergence could be illustrated in the second stage obviously, TG curve moves forward and degradation quickens with the increase of oxygen concentration. 


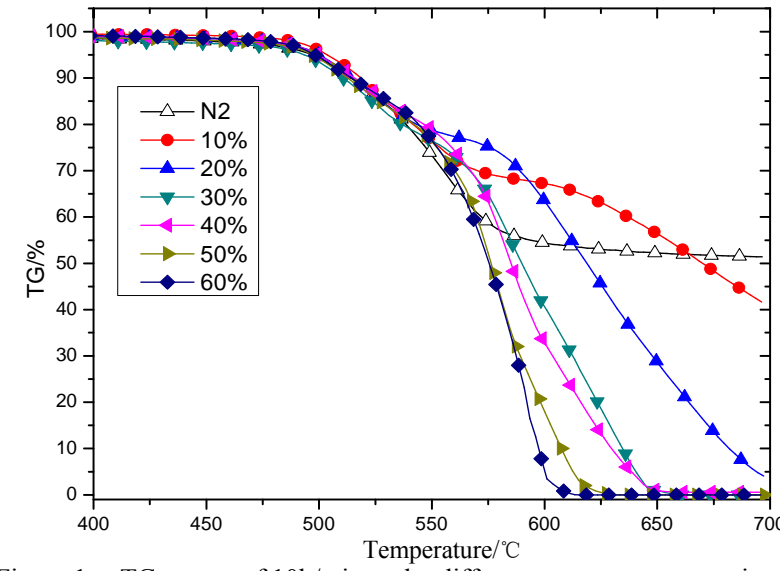

Figure 1. TG curves of $10 \mathrm{k} / \mathrm{min}$ under different oxygen concentration

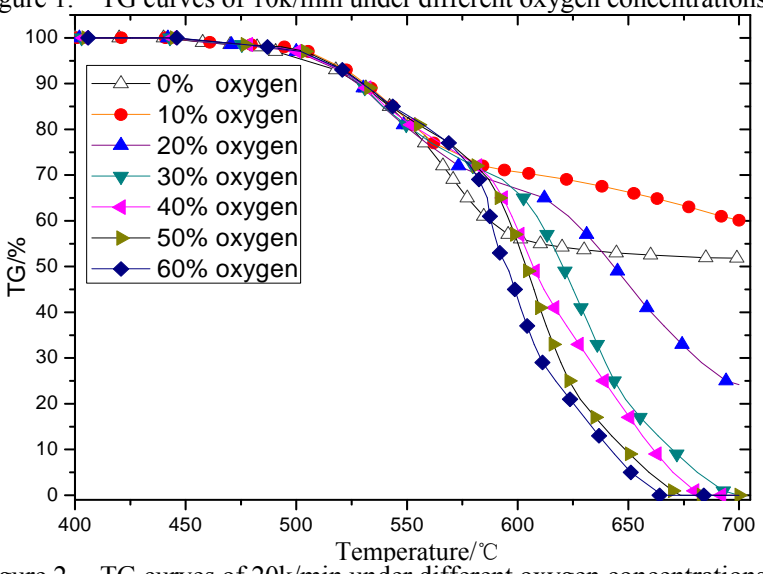

Figure 2. TG curves of $20 \mathrm{k} / \mathrm{min}$ under different oxygen concentrations

As is shown in Fig3 and Fig4,corresponding with two stages of TG curves, two peaks displayed on the derivative thermogravimetry(DTG) curves under oxidative atmosphere. Similarly, first stage of DTG curves is nearly overlapped while the peak temperature decreases and the temperature range of a whole weight loss peak narrows with the increase of oxygen concentration in second degradation stage. At the same time, in comparison with $10 \mathrm{k} / \mathrm{min}$, the peak temperature are higher and the peak range are wider at the heating rate of $20 \mathrm{k} / \mathrm{min}$, which is corresponding with the conclude of M.X.Fang[6].This phenomenon can be explained by thermal hysteresis quality under different heating rates, time of receiving heat is more adequate with the lower heating rate, then both of the initial and terminated temperature move toward lower direction.

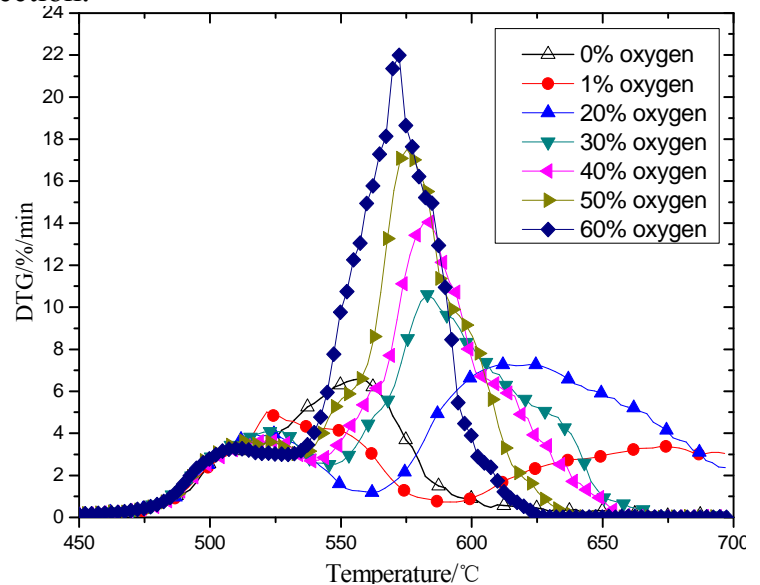

Figure 3. DTG curves of 10k/min under different oxygen concentrations

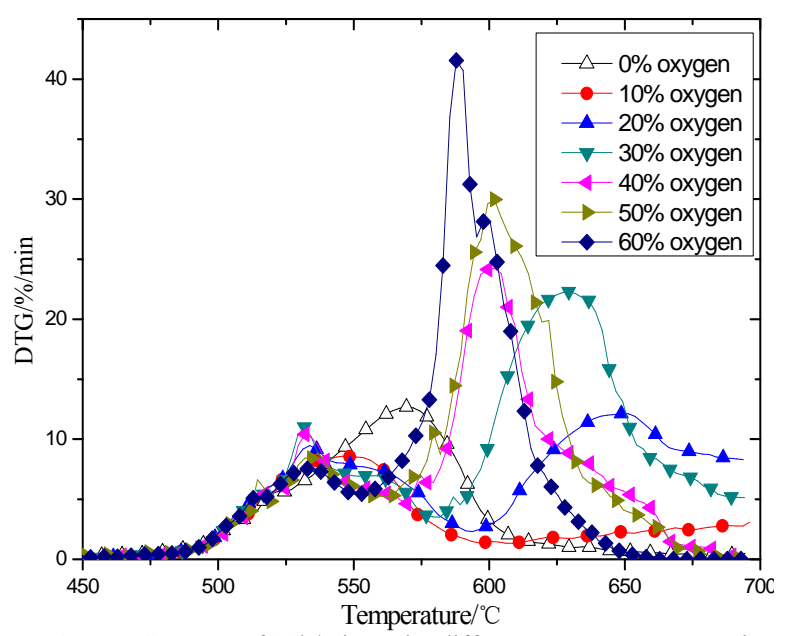

Figure 4. DTG curves of $20 \mathrm{k} / \mathrm{min}$ under different oxygen concentrations

Peak value of DTG in two stages of PPS under different oxidative atmosphere are showed in Fig5.The value of first stage vary little but in the second stage change distinctly with the increasing oxygen concentration, a strong linear relationship also be found between the maximal degradation rate and the oxygen concentration with the fitting degree of $0.986(\beta=10 \mathrm{~K} / \mathrm{min})$ and $0.942(\beta=20 \mathrm{~K} / \mathrm{min})$.

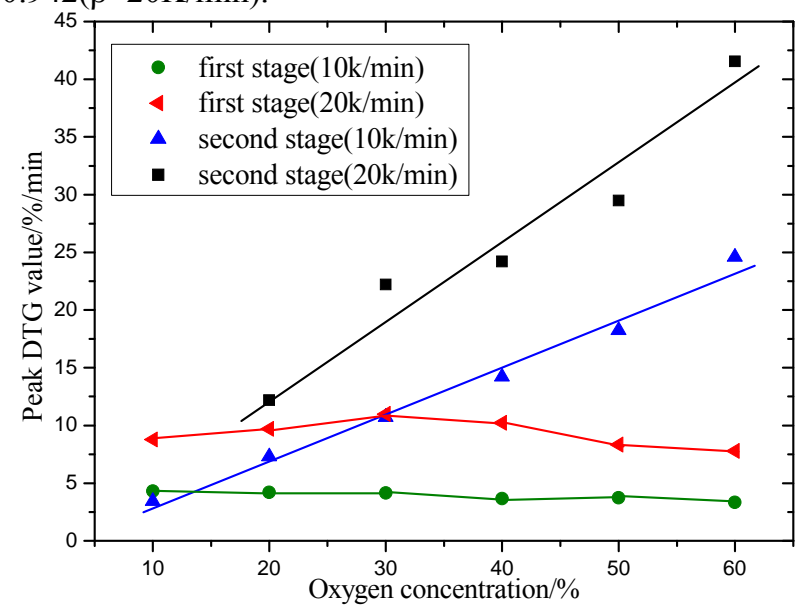

Figure 5. Peak DTG value of every stage under different oxygen concentrations

\section{B. Analysis based on Coats-Redfern method}

Coats-Redfern integral method has been generally used to analysis non-isothermal kinetic parameters by calculating data of a $\mathrm{TG}$ curve from a single heating rate[7][8][9].The kinetic equation can generally be written as equation (1):

$$
\frac{\mathrm{d} \alpha}{\mathrm{dt}}=\mathrm{k}(\mathrm{T}) \mathrm{f}(\alpha)
$$

$\mathrm{k}(\mathrm{T})$ is described by Arrhenius equation (2) as follows, which reveals the relation between reaction rate and temperature:

$$
\mathrm{k}=\mathrm{Ae} \mathrm{e}^{-\frac{\mathrm{E}}{\mathrm{RT}}}
$$


where $\mathrm{A}$ is the pre-exponential factor, $\mathrm{E}$ is the apparent activation energy and $R$ is the gas constant. $f(\alpha)$ follows the equation (3), where $n$ is the reaction order.

$$
f(\alpha)=(1-\alpha)^{n}
$$

Equation (4) shows the conversion rate $\alpha, \mathrm{m}_{\mathrm{t}}$ represent the weight of the sample corresponding to time $t ; \mathrm{m}_{\mathrm{i}}$ and $\mathrm{m}_{\infty}$ are the initial and terminate weight of the sample respectively[10].

$\alpha=\frac{m_{i}-m_{t}}{m_{i}-m_{\infty}}$

Plug equation (2) and equation (3) into equation (1) get equation (5):

$$
\frac{\mathrm{d} \alpha}{\mathrm{dt}}=\mathrm{Ae}^{-\frac{\mathrm{E}}{\mathrm{RT}}}(1-\alpha)^{\mathrm{n}}
$$

There Coats-Redfern equation can be obtained by integration of equation (5) as follows[11]:

$$
\begin{gathered}
\ln \left[\frac{1-(1-\alpha)^{1-n}}{T^{2}(1-n)}\right]=\ln \left[\frac{\mathrm{AR}}{\beta E}\left(1-\frac{2 \mathrm{RT}}{\mathrm{E}}\right)\right]-\frac{\mathrm{E}}{\mathrm{RT}}(\mathrm{n} \neq 1) \\
\ln \left[\frac{-\ln (1-\alpha)}{\mathrm{T}^{2}}\right]=\ln \left[\frac{\mathrm{AR}}{\beta \mathrm{E}}\left(1-\frac{2 \mathrm{RT}}{\mathrm{E}}\right)\right]-\frac{\mathrm{E}}{\mathrm{RT}}(\mathrm{n}=1)
\end{gathered}
$$

Where $\beta$ is the heating rate, for generally reaction precess, $\mathrm{E} / \mathrm{RT} \geq 1$ and therefore $1-2 \mathrm{RT} / \mathrm{E} \approx 1$, fitting the left of equation (6) and equation (7) versus $1 / \mathrm{T}$, the apparent activation energy $\mathrm{E}$ and pre-exponential factor $\mathrm{A}$ can be determined by slope and intercept respectively. Table1 shows the apparent activation energy and pre-exponential factor calculated by this method.

TABLEI. APPARENT ACTIVATION ENERGY CALCULATED BY COATS-REDFERN METHOD

\begin{tabular}{cccccc} 
& \multicolumn{6}{c}{ apparent activation energy and degree of fitting } \\
\cline { 2 - 6 } Atmosphere & $\boldsymbol{\beta}$ & $\boldsymbol{E}_{\boldsymbol{I}}$ & $\boldsymbol{R}^{2}$ & $\boldsymbol{E}_{\boldsymbol{2}}$ & $\boldsymbol{R}^{2}$ \\
\cline { 2 - 6 } & $\boldsymbol{K} / \boldsymbol{m} \boldsymbol{i n}$ & $\boldsymbol{k J} / \boldsymbol{m o l}$ & & $\boldsymbol{k J} / \boldsymbol{m o l}$ & \\
\hline $0 \% \mathrm{O}_{2}$ & 10 & 167.71 & 0.9979 & - & - \\
& 20 & 168.23 & 0.9992 & - & - \\
$10 \% \mathrm{O}_{2}$ & 10 & 168.02 & 0.9716 & 40.05 & 0.9980 \\
& 20 & 175.43 & 0.9771 & 19.41 & 0.9767 \\
$20 \% \mathrm{O}_{2}$ & 10 & 177.32 & 0.9747 & 119.39 & 0.9989 \\
& 20 & 178.52 & 0.9817 & 116.99 & 0.9980 \\
$30 \% \mathrm{O}_{2}$ & 10 & 175.18 & 0.9916 & 155.48 & 0.9978 \\
& 20 & 173.36 & 0.9711 & 162.05 & 0.9905 \\
$40 \% \mathrm{O}_{2}$ & 10 & 159.17 & 0.9727 & 221.14 & 0.9959 \\
& 20 & 177.87 & 0.9700 & 197.05 & 0.9916 \\
$50 \% \mathrm{O}_{2}$ & 10 & 163.27 & 0.9760 & 232.27 & 0.9961 \\
& 20 & 179.95 & 0.9743 & 240.69 & 0.9928 \\
$60 \% \mathrm{O}_{2}$ & 10 & 153.90 & 0.9798 & 270.41 & 0.9864 \\
& 20 & 163.73 & 0.9732 & 308.22 & 0.9920 \\
\hline
\end{tabular}

Apparent activation energy of the second pyrolysis stage increases with the increasing oxygen concentration with the same heating rate.A strong linear relationship between apparent activation energy of the second stage and oxygen concentration can be found,with the fitting degree of $0.956(\beta=10 \mathrm{k} / \mathrm{min})$ and $0.973(\beta=20 \mathrm{k} / \mathrm{min})$ showed in Fig.6.Apparent activation energy of the first degradation stage fluctuates around $170 \mathrm{~kJ} / \mathrm{mol}$.

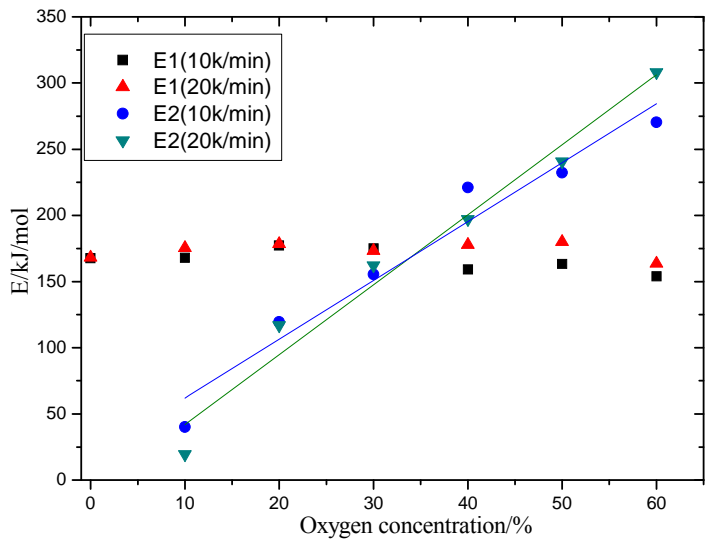

Figure 6. Change rules of activation energy calculated by Coats-Redfern method

\section{Analysis of the kinetic compensation effect}

Apparent activation energy and pre-exponential factor calculated above increase with increasing oxygen concentration. The mathematical expression of kinetic compensation effect can be described as $\ln \mathrm{A}=\mathrm{aE}+\mathrm{b}[7][12]$, which denotes that the pre-exponential factor increase with the increasing activation energy. Equation (8) can be transformed from the formula of kinetic compensation effect:

$$
\mathrm{A}=\mathrm{C}_{0} \mathrm{e}^{\mathrm{aE}}
$$

Where $C_{0}=\mathrm{e}^{b}$ is constant term, then plug equation (8) into equation (2) and the relationship between reaction rate $\mathrm{K}$ and activation energy $\mathrm{E}$ can be described as equation (9):

$$
\mathrm{K}=\mathrm{C}_{0} \mathrm{e}^{\mathrm{E}\left(\mathrm{a}-\frac{1}{\mathrm{RT}}\right)}
$$

The temperature $T=\frac{1}{a R}$ is called isokinetic temperature which can be denoted as $\mathrm{T}_{\mathrm{S}}$, and the effect of activation energy on reaction rate mainly include two aspects[13]:

1. When $\mathrm{T}<\mathrm{T}_{\mathrm{S}}$, the coefficient $\alpha-\frac{1}{R T}>0$, and then the reaction rate $\mathrm{K}$ decreases with the increase of activation energy E.

2. When $\mathrm{T}>\mathrm{T}_{\mathrm{S}}$, the coefficient $\alpha-\frac{1}{R T}<0$, and then the reaction rate $\mathrm{K}$ decreases with the increase of activation energy E.

Obvious kinetic compensation effect also discovered according to the solved kinetic parameters of polyphenylene sulfide under different oxygen concentrations. The linear fitting of $\ln \mathrm{A}$ and $\mathrm{E}$ is carried out based on the parameters in Table III and described as Table II and Fig.7, calculated isokinetic temperature $\mathrm{T}_{\mathrm{S}}$ is $505^{\circ} \mathrm{Cand} 522.4^{\circ} \mathrm{C}$ 
respectively when heating rate is $10 \mathrm{k} / \mathrm{min}$ and $20 \mathrm{k} / \mathrm{min}$. The temperature corresponding to second pyrolysis stage is greater than $T_{S}$, therefore the degradation rate of PPS increases with the increase of activation energy.

TABLEII. KINETIC COMPENSATION EFFECT FORMULA OF PPS

\begin{tabular}{cccc}
\hline$\beta(\mathrm{K} / \mathrm{min})$ & Linear formula & $\mathrm{R}^{2}$ & $\mathrm{~T}_{\mathrm{S}}\left({ }^{\circ} \mathrm{C}\right)$ \\
\hline 10 & $\ln \mathrm{A}=0.1546 \mathrm{E}-11.32$ & 0.9999 & 505 \\
20 & $\ln \mathrm{A}=0.1512 \mathrm{E}-11.38$ & 0.9999 & 522.4 \\
\hline
\end{tabular}

TABLEIII. PRE-EXPONENTIAL FACTOR CALCULATED BY COATS-REDFERN METHOD

\begin{tabular}{|c|c|c|c|}
\hline \multirow{3}{*}{ Atmosphere } & \multicolumn{3}{|c|}{ Pre-exponential factor } \\
\hline & $\beta$ & $A_{1}$ & $A_{2}$ \\
\hline & $\mathrm{K} / \mathrm{min}$ & $\min ^{-1}$ & $\min ^{-1}$ \\
\hline \multirow{2}{*}{$10 \% \mathrm{O}_{2}$} & 10 & $4.31 \times 10^{6}$ & $0.52 \times 10^{-2}$ \\
\hline & 20 & $1.74 \times 10^{7}$ & $0.18 \times 10^{-3}$ \\
\hline \multirow{2}{*}{$20 \% \mathrm{O}_{2}$} & 10 & $2.05 \times 10^{7}$ & $1.21 \times 10^{3}$ \\
\hline & 20 & $3.23 \times 10^{7}$ & $6.55 \times 10^{2}$ \\
\hline \multirow{2}{*}{$30 \% \mathrm{O}_{2}$} & 10 & $1.75 \times 10^{7}$ & $4.37 \times 10^{5}$ \\
\hline & 20 & $1.4 \times 10^{7}$ & $5.21 \times 10^{5}$ \\
\hline \multirow{2}{*}{$40 \% \mathrm{O}_{2}$} & 10 & $1.13 \times 10^{6}$ & $8.50 \times 10^{9}$ \\
\hline & 20 & $2.74 \times 10^{7}$ & $1.19 \times 10^{8}$ \\
\hline \multirow{2}{*}{$50 \% \mathrm{O}_{2}$} & 10 & $2.38 \times 10^{6}$ & $5.14 \times 10^{10}$ \\
\hline & 20 & $3.60 \times 10^{7}$ & $7.02 \times 10^{10}$ \\
\hline \multirow{2}{*}{$60 \% \mathrm{O}_{2}$} & 10 & $5.03 \times 10^{5}$ & $1.45 \times 10^{13}$ \\
\hline & 20 & $2.92 \times 10^{6}$ & $1.69 \times 10^{15}$ \\
\hline
\end{tabular}

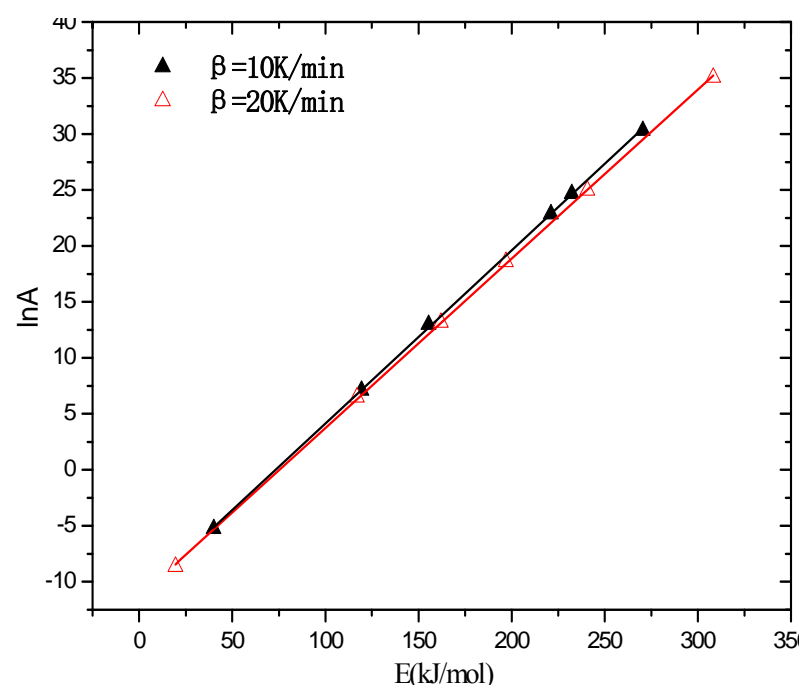

Figure 7. The kinetic compensation effect analysis curves of PPS

\section{CONCLUSIONS}

1)Only one stage occurs in inert atmosphere while two stages occur in oxidative atmosphere in the pyrolysis process of polyphenylene sulfide. Initial degradation temperature of first stage remains at around $480^{\circ} \mathrm{C}$ and increasing oxygen concentration decreases the initial and terminate temperature of second stage.

2)Maximal mass loss rate of first degradation stage stabilizes $(4.3 \pm 0.5) \% \bullet \mathrm{min}^{-1}$, apparent activation energy of the first degradation stage fluctuate around $170 \mathrm{~kJ} \cdot \mathrm{mol}^{-1}$ while both increase linearly with oxygen concentration in second stage.

3)Since the kinetic and pyrolysis parameters follow kinetic compensation effect and the temperature range of second stage is greater than isokinetic temperature, both of the apparent activation energy and degradation rate increase with the increasing oxygen concentrations, and isokinetic temperature $\mathrm{T}_{\mathrm{S}}$ is $505^{\circ} \mathrm{C}$ and $522.4^{\circ} \mathrm{Crespectively}$ when heating rate is $10 \mathrm{k} \cdot \mathrm{min}^{-1}$ and $20 \mathrm{k} \cdot \mathrm{min}^{-1}$

\section{REFERENCES}

[1] Edmonds J. T., Jr. And Hill H. w. Production of polymers from aromation compounds [P].U.S.A:3354129,1967-11-27.

[2] Pemg L. H. Thermal decomposition characteristics of poly (phenylene sulfide) by stepwise Py-GC/MS and TG/MS techniques[J].Polym.Degrad.Stab.,2000,69(3):323-332.

[3] SUN Pei, SUN Runjun. A contrast performance study on flame retardant fibers PPS and Aramid fiber 1313[J]. Shanghai Textile Science\&Technology,2008, 36(4):51-53.

[4] ZHANG Hao, MA Haiyan, HU Zuming. Study on the TG-DSC and heat-treatment of polyphenylene sulfide fiber[J].Synthetic Fiber in China,2007(4):25-29.

[5] LAI M F,YANG H L,LUAN Y C. Effect of PMR-POI on the melt behavior and isothermal crystallization of poly(phenylene sulfide) [J].Journal of Applied Polymer Science,2002,86:436-442

[6] M.X. Fang, Y. X. Li. Kinetic study on pyrolysis and combustion of wood under different oxygen concentrations by using TG-FTIR analysis[J].J.Anal.Appl.Pyrolysis, 2006,77:22-27

[7] Fuying Ma, YelinZeng. Thermogravimetric study and kinetic analysis of fungal pretreated corn stover using the distributed energy model. Bioresource Technology, 2013, 128: 417-422.

[8] Sutcu H, Piskin S. Characterization and combustion kinetics of chars obtained from loquat stones. Combust SciTechnol 2009; 181: 264-73.

[9] Li C, Suzuki K. Kinetic of perovskite catalyzed biomass tar combustion studied by thermogravimetry and differential thermal analysis.Energy Fuels 2009; 23: 2364-9.

[10] Zuru AA,DamgoggoSM,Birnin-Yauri UA,Tambuwal AD.Adoption of thermogravimetric kinetic models for kinetic analysis of biogas production.Renew Energy 2004,29(1):97-107.

[11] Coats-a,Redfern J.Kinetic parameters from thermogravimetric data.Nature 1964;201:68-9.

[12] Chun Zou, Liang Zhang. A study of combustion characteristics of pulverized coal in $\mathrm{O}_{2} / \mathrm{H}_{2} \mathrm{O}$ atmosphere [J]. Fuel,2014,115:312-320

[13] Hanxian Guo. Applied Chemical Industry Dynamics[M].Chemical Industry Press. 2003. 